\title{
Review on BOD/COD Ratio Toxicity to Daphnia magna, Artemia salina and Brachydanio rerio
}

\author{
Latifa Mirzatika Al-Rosyid**†, Harmin Sulistiyaning Titah*, Irwan Bagyo Santoso* and \\ Sarwoko Mangkoedihardjo* \\ *Department of Environmental Engineering, Faculty of Civil, Environmental, Geo Engineering, Institut Teknologi \\ Sepuluh Nopember (ITS), Sukolilo, 60111 Surabaya, Indonesia \\ **Department of Civil Engineering, Faculty of Engineering, University of Muhammadiyah Jember, 68121, Jember, \\ Indonesia \\ †Corresponding author: Latifa Mirzatika Al-Rosyid; latifamirzatika@gmail.com
}

\section{Nat. Env. \& Poll. Tech \\ Received: 09-01-2021 \\ Revised: 26-02-2021 \\ Accepted: 12-04-2021 \\ Key Words: \\ BOD/COD ratio \\ Artemia salina \\ Brachydanio rerio \\ Daphnia magna \\ Toxicity}

Website: www.neptjournal.com

\section{ABSTRACT}

This paper review research works on BOD/COD ratio toxicity to three bioindicators, namely: Daphnia magna, Artemia salina, and Brachydanio rerio. Treatment methods are divided into natural, biological, physical, chemical, combined treatment, and phytotechnology for various types of processing operations such as municipal and industrial wastewater treatment plants, various effluent treatment, landfill leachate, and organic matter. $A$. salina shows the lowest toxicity value of the BOD/COD ratio and shows it can withstand processing conditions that are not biodegradable. Then followed by $B$. rerio and $D$. magna. Furthermore, the disposal limits are standardized for the protection of freshwater biota. In addition, it must be considered whether there is any other potential of disposal into the receiving environment, and if so, what form of disposal and how much, to protect the biota.

\section{INTRODUCTION}

Toxicology is an understanding of the effects of chemicals that are detrimental to living organisms (Moreno 2018, Li et al. 2018). There are elements in toxicology that interact in specific ways to generate a response in a biological system that can cause damage to the biological system (Xue et al. 2019). Toxicology is divided into pharmacotoxicology and ecotoxicology (Arslan \& Karaaslan 2016). This paper discusses ecotoxicology. Ecotoxicology studies the effects of pollutants on life and their effects on ecosystems, which can be used to evaluate the relationship between humans and pollutants that exist around the environment (Cardete et al. 2019). In line with quantity complexity, organic matter has pollutant quality complexity (Paris \& Mangkoedihardjo 2020). The BOD/COD ratio itself indicates the biodegradability of wastewater, where the higher the ratio the lower the biodegradability of wastewater (Dincer 2020).

A number of Daphnidae family species are commonly used in toxicity tests. Besides being recommended for testing, this organism is available all year round and is easily cultivated in the laboratory (USEPA 2019). D. magna is a small invertebrate crustacean and is the main food source for many fish in freshwater ecosystems (Sa et al. 2018, Bekker et al. 2018, Kruppert et al. 2017). As much as $41.24 \%$ of all known fish species are obtained in freshwater (Marzan et al. 2014). In addition, D. magna is sensitive to various pollutants and has been widely used as a bio-indicator organism to evaluate various toxic substances (Yan \& Chen 2019, Leppanen 2018, Huang et al. 2017, Yasser et al. 2015). This study investigates the acute and chronic toxicity of numerous compounds to aquatic species, with a focus on D. magna standard test organisms, with the aim of reducing potential environmental concerns (Borujeni et al. 2018, Xavier et al. 2017, Kocbas \& Oral 2015).

Bioindicators based on A. salina were used to assess the toxicity of chemicals found in unprocessed and persistent environments (Borba et al. 2019). Rajabi et al. (2015), reported A. salina as a bioindicator of toxicity has advantages compared to indirect methods including high sensitivity to toxic substances, fast response, and low cost. A. salina is a simple organism from marine biota that is very small and has a high sensitivity to toxins. Research shows that A. salina has a positive correlation with bioactive extracts (Arun et al. 2019, Cabrera 2017). 
B. rerio is used as a representation of freshwater organisms in toxicity tests, recommended as an organism model according to OECD guidelines (OECD 2019), and has been widely used in toxicology testing (Panzica-Kelly et al. 2015, Boix et al. 2020). B. rerio is commonly used in ecotoxicological studies, because of its biological and reproductive properties (short generation and spawning intervals) that are suitable as test fish for toxicological studies (Bambino \& Chu 2017). In ecology, B. rerio swimming behavior in motility characteristics is an external reaction caused by internal changes, as well as behavioral responses related to environmental pressures, which can provide the latest ecological information in toxicological assessment (Ren et al. 2015). B. rerio and D. magna, have been used throughout the wastewater toxicity (WET) program to evaluate the removal of acute toxicity of wastewater during anaerobic-anoxic-oxic (A / A / O) (Smol et al. 2018, Deng et al. 2016, USEPA 2016).

Biochemical Oxygen Demand (BOD) and Chemical Oxygen Demand (COD) are the most widely used parameters in the classification of wastewater, each of which has advantages and disadvantages. The choice depends on several factors, namely the time needed to determine each factor itself. Obtaining a correlation between BOD and COD for various wastewater treatment plants is important so that it can help in plant design and operation (Abdalla \& Gina 2014). Therefore, the BOD/COD ratio becomes meaningless without knowing the intended use. In line with the quantity complexity, organic matter has a complex quality of pollutants (Paris \& Mangkoedihardjo 2020). The BOD/COD ratio indicates the level of wastewater biodegradability; the higher the ratio, the lower the biodegradability of the wastewater (Dincer 2020). However, the researchers used the BOD/ COD ratio to describe the level of biodegradability where organic matter containing wastewater decreases the quality of the environment.

This paper review research works on various operating treatment conditions, attempting to figure out BOD/COD ratio toxicity to three bioindicators i.e. D. magna, A. salina, and $B$. rerio. Treatment methods are divided into natural, biological, physical, chemical, combined treatment, and phytotechnology for various types of processing operations such as municipal and industrial wastewater treatment plants, various effluent treatment, landfill leachate, and organic matter.

In the literature, several review studies have focused on the treatment methods, bioindicator, and the BOD/COD ratio toxicity. However, to the best of our knowledge, studies concerning the various operating treatment conditions of three bioindicators have not been reviewed in detail. This study reviews the state-of-the-art of various operating treatments and examines $\mathrm{BOD} / \mathrm{COD}$ ratio toxicity to three bioindicators. In this regard, the BOD/COD ratio toxicity to three bioindicators i.e., D. magna, A. salina, and B. rerio by various operating treatment conditions is presented. Then, the characterization of wastewater, treatment methods, major challenges, and future prospects are discussed in detail.

\section{MATERIALS AND METHODS}

The methods applied in this literature review included identification of the relevant studies and preparing a set of questions to be addressed to selected literature relevant to the scope of this review. Identification of relevant literature was performed by searching in Science Direct, Scopus, and Google Scholar using the following keywords: "BOD/COD ratio", "toxicity", "B. rerio", "D. magna" and "A. salina". After that, the generated literature list was checked manually (reading materials and methods and results) to exclude studies, in which (i) various operating treatment conditions were used; (ii) toxicity assessment of wastewater before and after treatment was not conducted. Moreover, literature reviews were not considered. It should be noticed that only relevant articles published during the period 2010-2020 were included in this review. Moreover, relevant studies found during screening other studies were included in the list during the literature identifying step. The literature search was limited to articles published in peer-reviewed journals in the English language. Reports published in other languages, as well as books, were excluded from the literature search.

\section{RESULTS AND DISCUSSION}

\section{Daphnia magna as a Test Species}

\section{Complex industrial wastewater}

D. magna is used as an assessor and comparison of toxicity between influent wastewater and liquid waste from the activated sludge process, and to compare its relationship with physical-chemical parameters namely BOD and COD. The average ratio of BOD/COD is $0.54-0.66$, respectively. This shows the amount of high-level material that cannot be decomposed naturally. Very large reductions in BOD are observed between influent and effluent. D. magna evaluates high toxicity in waste, indicating that BOD is not the main source of toxicity. The best correlation between bioindicator responses and chemical tests was obtained between nitrogen compounds and COD with D. magna in samples from secondary clarifiers. The results of the toxicity test showed that although there was a decrease in the toxicity response to D. magna, there were still potential negative effects on the growth of plant roots that could affect plant production (Yan $\&$ Chen 2019). No correlation was obtained between the test 
results in primary (influent) clarification, but the tendency for correlation was obtained in secondary (effluent) clarification with COD parameters.

\section{Treated Kraft Mill Effluents}

Waste from kraft factories treated using activated sludge shows a reduction in acute toxicity. Waste from the kraft pulp mill has been identified as a potential contaminant in the aquatic environment (Chamorro et al. 2016, Peitz \& Xavier 2020, Kocbas \& Oral 2015). The nature of their compounds comes from the existence of several naturally occurring xenobiotic compounds, which are formed and released during several stages of the process (Koppel et al. 2017). The value of the COD/BOD ratio of each effect is $0.34-0.39$. This indicates that there are high concentrations of recalcitrant compounds, such as phenolic compounds, tannins, and lignin, among other compounds (Xavier et al. 2017, Peitz \& Xavier 2020). The results showed that the effect of kraft mill wastewater treatment indicated acute toxicity of $\mathrm{LC}_{15-24 \mathrm{~h}}$ for D. magna at $71.72 \%$. While $\mathrm{LC}_{15-48 \mathrm{~h}}$ for $D$. magna shows acute toxicity with a value of $20.58 \%$. In this case, it can be seen that there are different sensibilities. The research results obtained that the treatment of activated sludge can eliminate at $100 \%$ acute (Kocbas \& Oral 2015, Velásquez-Riaño et al. 2019).

\section{Municipal Wastewater Treatment Plant}

An acute toxicity test is carried out to evaluate the relationship between the physical-chemical parameters of the waste and its toxicity in the wastewater treatment plant. Toxicity tests are carried out at wastewater treatment plants under various operational conditions (Borujeni et al. 2018). The average BOD5/COD ratio of each 0.5 - 0.6 was calculated. After 96 hours of exposure, D. magna was damaged. The effluent can be safely discharged to surface water with respect to physical-chemical parameters and acute toxicity units (TUa). The relationship between effluent COD and $\mathrm{LC}_{50}-24 \mathrm{hr}$ showed an increase in effluent COD results in increased wastewater toxicity, whereas between $\mathrm{BOD}_{5}$ and effluent toxicity, no relationship was found.

\section{Municipal Wastewater Treatment Plant Effluents on Freshwater}

BOD and COD values in MMWTP wastewater decreased after treatment. This shows that the processing system is working perfectly (Kocbas \& Oral 2015). The average value of the BOD/COD ratio was obtained between 0.33 to 0.36 . Eco toxicity test results show the mobility of $D$. magna ranges from 0 to $100 \%$ in untreated systems and 15 to $100 \%$ after being treated (Mendonça et al. 2013). The physical-chemical parameters measured in wastewater show a significant decrease in value. Meanwhile, D. magna did not show the same reduction in toxicity tests. Even for a short amount of time, none of the Daphnia individuals are allowed to exist in $100 \%$ untreated liquid waste and survive.

However, the toxicity value in immobilized D. magna was defined as LC50 and TU with different testing times. Although all MMWTP wastewater is released in accordance with rules for conventional water quality standards, all waste toxicity testing using D. magna indicates that it is harmful. In addition, the increase in biological toxic effects is based on the time of exposure to the test. The LC50 value of the test carried out on untreated wastewater is 24.9 after 24 hours. After that, each dropped according to the TU value. The water treated in D. magna immobilization is less toxic than untreated water. However, the toxic effects of treated wastewater on D. mag$n a$ increase over a longer period, similar to water not treated before. Although the LC50 value has decreased each.

Of the various types of treatment for Daphnia, the range of toxicity ratios of $\mathrm{BOD}_{5} / \mathrm{COD}$ that have the most effective effect are $0.3-0.6$, respectively (Fig. 1).

\section{Artemia salina as a Test Species}

\section{Paper Pulp and Mill Wastewater Treatment}

The combined treatment of post-bleaching effluents resulted in a BOD/COD ratio of 0.11 to 0.14 , respectively. Transparency, colorless and smelly treated water, shows good water quality (Cabrera 2017). A. salina bioindicator shows that the expressive decrease in toxic pollutants in the waste occurs after treatment, mainly by a combined process, namely coagulation followed by photocatalysis. Wastewater treatment is carried out together under optimal experimental conditions, giving satisfying results.

\section{Sugar Industry Effluent Treatment}

A. salina is used as a bioindicator in the processing of the sugar industry waste. In 60 ppt saline media, A. salina, used as a bioindicator for secondary treatment of refining waste, can remove up to 69 percent of total solids and 33.34 percent of BOD. After treatment with A. salina, liquid waste showed a significant $\mathrm{p}<0.001$. Obtained COD reduced from a minimum of $14 \%$ and then a maximum of $4 \%$ (El Fels et al. 2016). The average value of the BOD/COD ratio is obtained for each of $0.14-0.19$. TDS is measured after each processing stage and shows promising results with A. salina, which has the ability to control industrial waste contamination.

\section{Industrial Wastewater}

The aerobic process is used for treating wastewater from tannery using A. salina. A. salina is harvested at the age of 15 days after cysts are inoculated in the hatching tank. 63.09 $\mathrm{g}$ (wet weight) A. salina was put together in a tank with a 


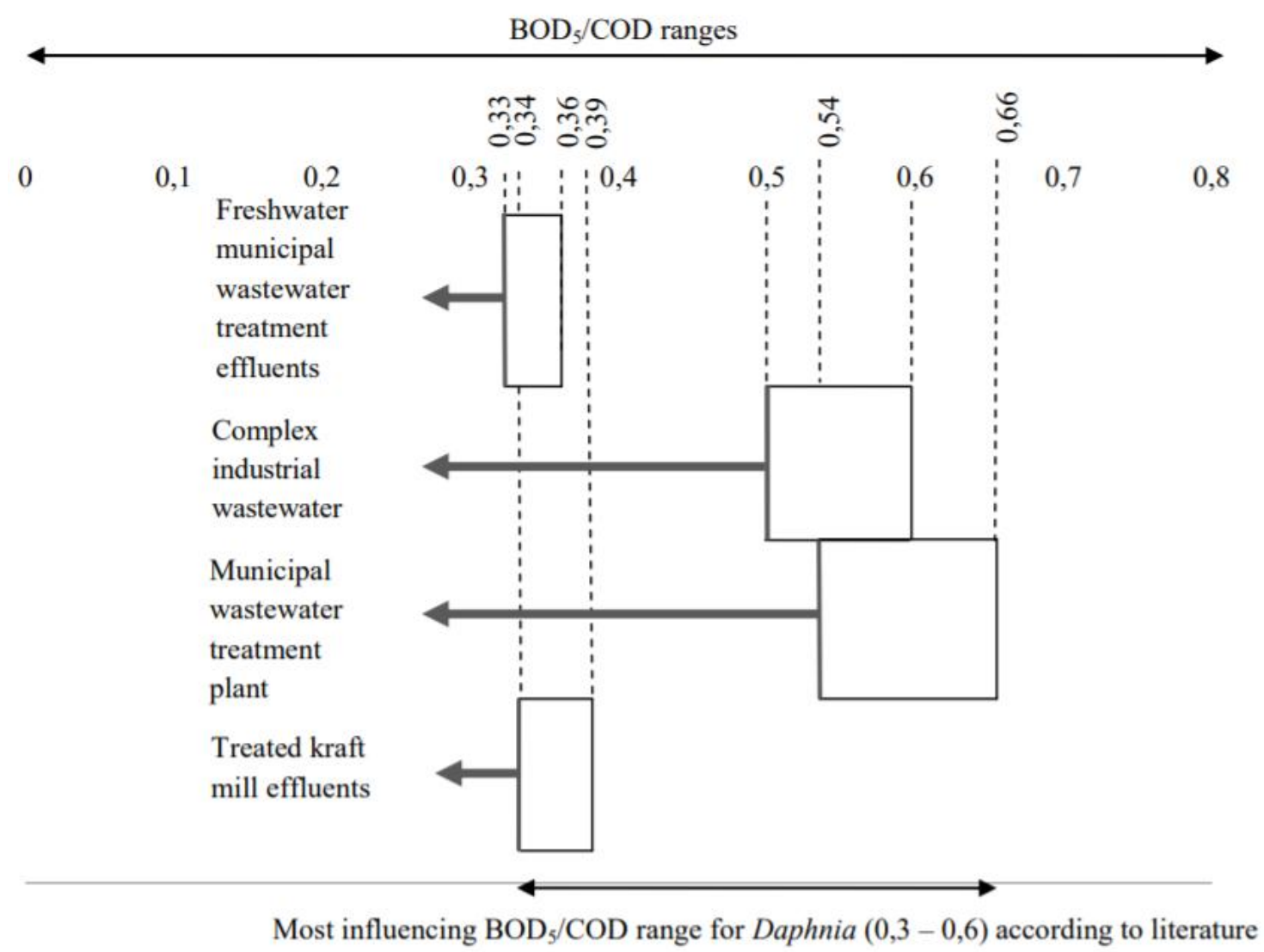

Fig. 1: BOD/COD ratio range yielding maximum removal of Daphnia magna as reported in the literature.

weight of $0.0036 \mathrm{~g}$ each (Arun et al. 2019). The average value of the BOD5/COD ratio was obtained for each of $0.12-0.17$. This is safe within the limits permitted and suitable for disposal into water bodies and recommended for reuse.

From various types of treatments for A. salina, the most effective range to the toxicity ratio of $\mathrm{BOD} / \mathrm{COD}$ is 0.11 0.19, respectively (Fig. 2).

\section{Brachydanio rerio as a Test Species}

\section{Organic Matter}

The BOD/COD ratio shows that glucose, lactose, and sucrose can decompose naturally, while formaldehyde, acetic acid, and oxalic acid, cannot decompose naturally. This result is supported by a toxicity test, which shows that all three are more toxic than substances that can be decomposed naturally (Al-Rosyid \& Mangkoedihardjo 2019). The average value of the BOD/COD ratio was obtained for each $0.08-0.25$. Formaldehyde has the smallest LC50-96h, which is 23.99 so that $B$. rerio response with the highest mortality is obtained. This is consistent with the biodegradability of formaldehyde which is included in the category of non-biodegradable. Lactose with the largest LC50-96h value is 851.14 and is included in the biodegradable category in laboratory analysis. This also corresponds to lactose biodegradability which is included in the biodegradable category.

\section{Landfill Leachate}

Leachate contains a number of distinct properties, including a high level of salinity and low biodegradability. (BOD/ COD 0.05). Initially, physical-chemical processing was used, while the second stage consisted of ozone application to improve leachate biodegradability. The final stage consists of biological processing. Stages of the processing carried out bring good results, with an increase in the ratio of BOD/ COD from 0.05 to 0.3 after ozonation (Grosser et al. 2019). Toxicity analysis conducted using various bioindicators such as $B$. rerio has confirmed the potential danger of landfill leachate (Ghosh et al. 2017, Sackey \& Koci 2020) and the need to process it so that it meets the disposal standards in water bodies. Biological treatment processes, including aerobic and anaerobic processes, are quite effective for leachate produced in the initial stages, with high BOD/COD ( $\mathrm{Li}$ et al. 2010). However, in general, it has not been successful in treating leachate with BOD/COD which is rather low, 


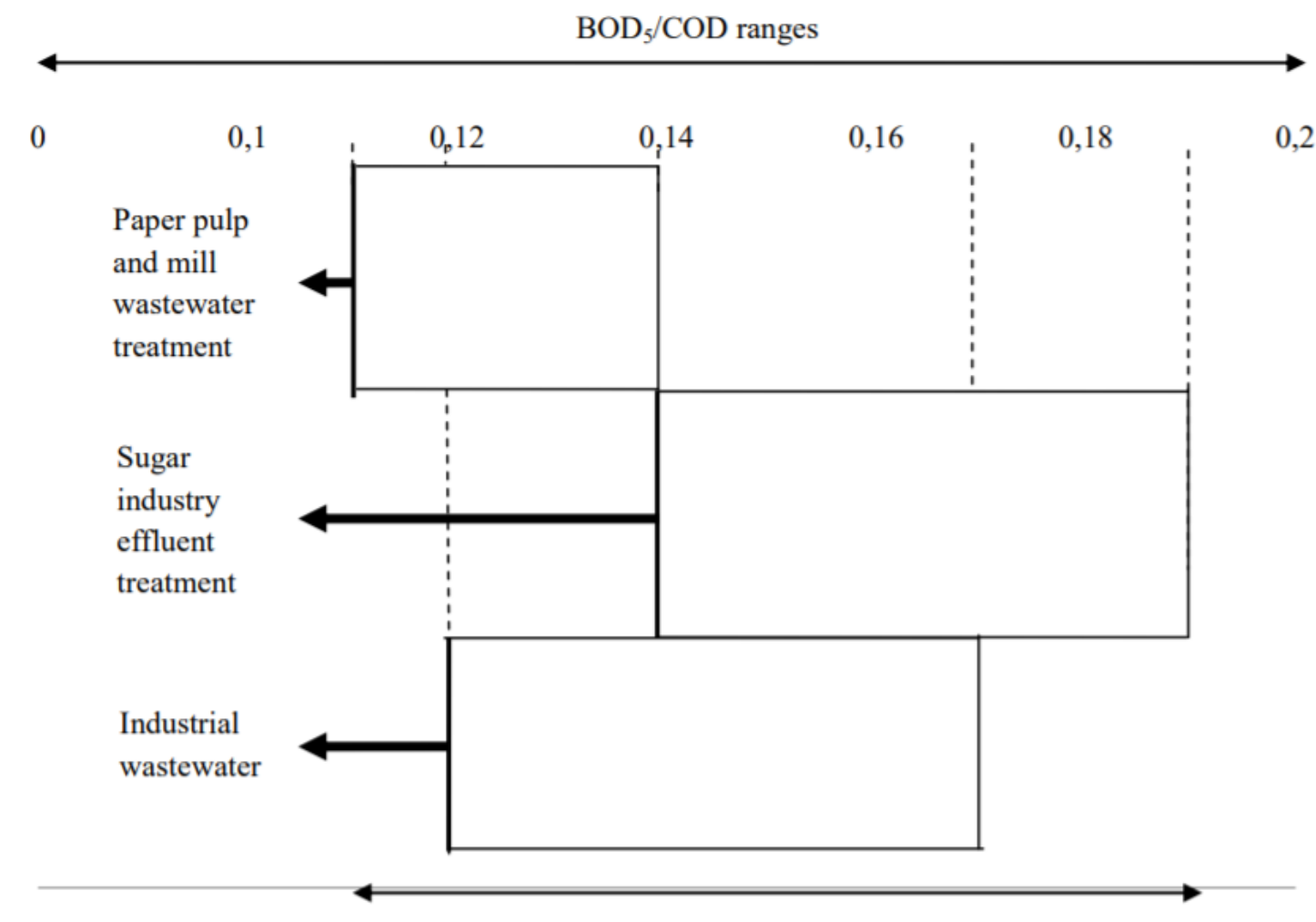

Most influencing $\mathrm{BOD}_{5} / \mathrm{COD}$ range for Artemia $(0,11-0,19)$ according to literature

Fig. 2: BOD/COD ratio range yielding maximum removal of Artemia salina as reported in the literature.

or high heavy metal concentrations (Banch et al. 2020). Therefore, physical-chemical processes are mostly used for pretreatment or full treatment for leachate types in landfills.

From the various types of processing for $B$. rerio, the most effective range influenced the toxicity ratio of BOD5/ COD, ranging from 0.05 to 0.3 . (Fig. 3).

Comparison Ranges for Daphnia magna, Artemia salina, and Brachydanio rerio

Each of the three types of bioindicators used, D. magna, A. salina, and B. rerio, has an effective BOD/COD range, with D. magna, A. salina, and B. rerio having the highest influence in their respective processing conditions. D. magna has a range of $\mathrm{BOD} / \mathrm{COD}$ which results in a maximum reduction of 0.3 - 0.6, for complex industrial wastewater, kraft mill effluents treated, municipal wastewater treatment plants, and municipal wastewater treatment plants in freshwater. A. salina has a range of $\mathrm{BOD} / \mathrm{COD}$ which results in a maximum reduction of $0.11-0.19$, for paper and mill wastewater treatment, sugar industry wastewater treatment, and industrial wastewater. $B$. rerio has a range of $\mathrm{BOD} /$ COD ratios resulting in a maximum reduction of $0.05-0.3$, respectively, for organic matter and landfill leachate. $A$. salina shows the lowest toxicity value of the BOD/COD ratio. This shows that it can withstand processing conditions that cannot be decomposed naturally. Then followed by $B$. rerio and D. magna (Fig. 4).

\section{CONCLUSIONS}

This review indicates the future role of $A$. salina bioindicators in aquatic toxicology testing, where A. salina can be a reference or quality control in rapid screening tests, as well as predictors of chemical effects on species in the marine environment. Toxicity tests conducted using $B$. rerio show that leachate toxicity is hardly reduced by ozonation. This result is consistent with the fact that although the BOD/COD ratio is higher, biological processes do not show better processing performance. In conclusion, the researchers suggest that toxicity calculation and monitoring of physical-chemical parameters are carried out together in large-scale processing plants. Furthermore, the disposal limits are standardized for the protection of freshwater biota. Furthermore, it must be considered whether additional disposal into the receiving environment is possible, and if so, what form of disposal and how much is possible, so that the biota is preserved. 


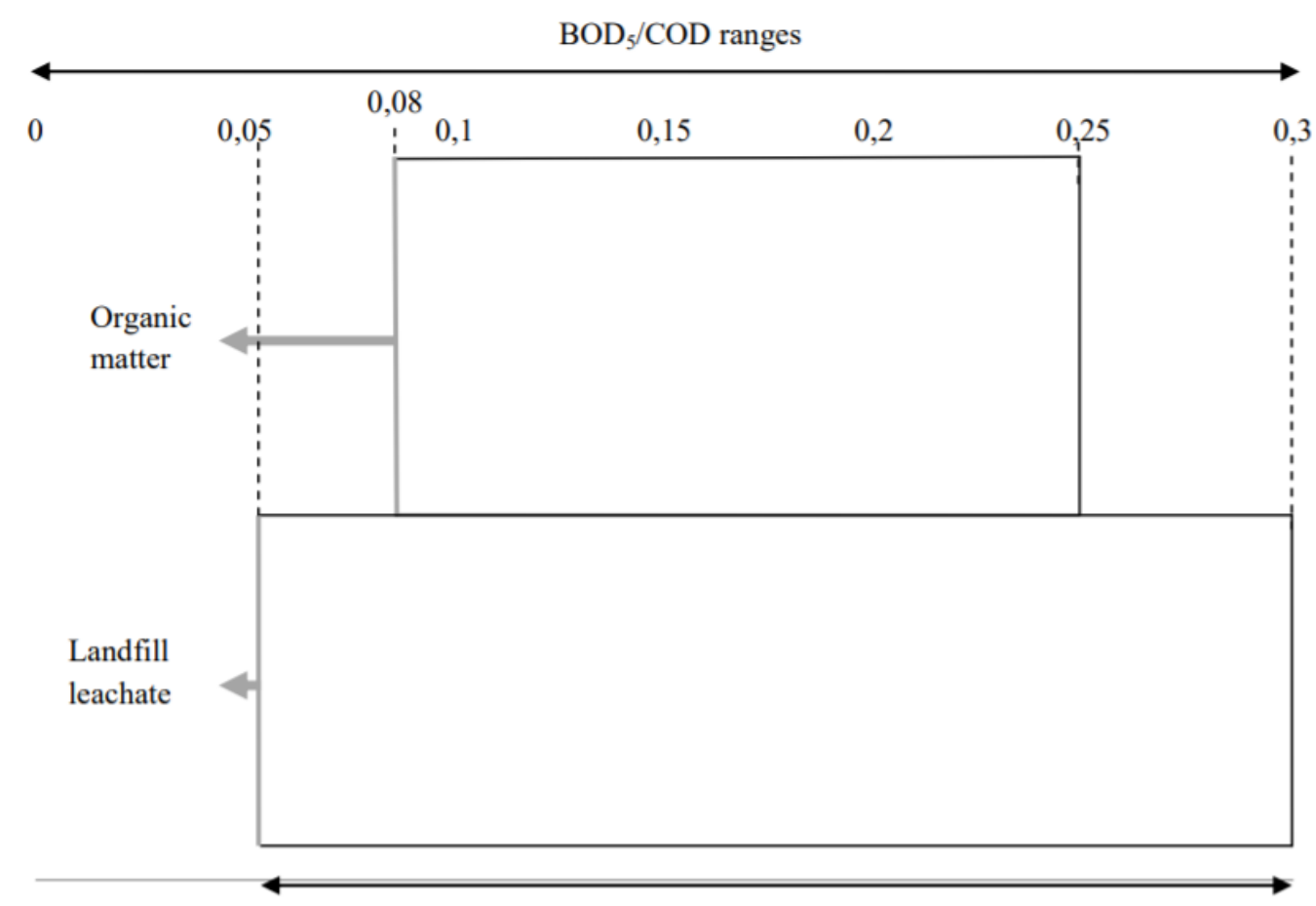

Most influencing $\mathrm{BOD}_{5} / \mathrm{COD}$ range for Brachydanio rerio $(0,05-0,3)$ according to literature

Fig. 3: BOD/COD ratio range yielding maximum removal of Brachydanio rerio as reported in the literature.

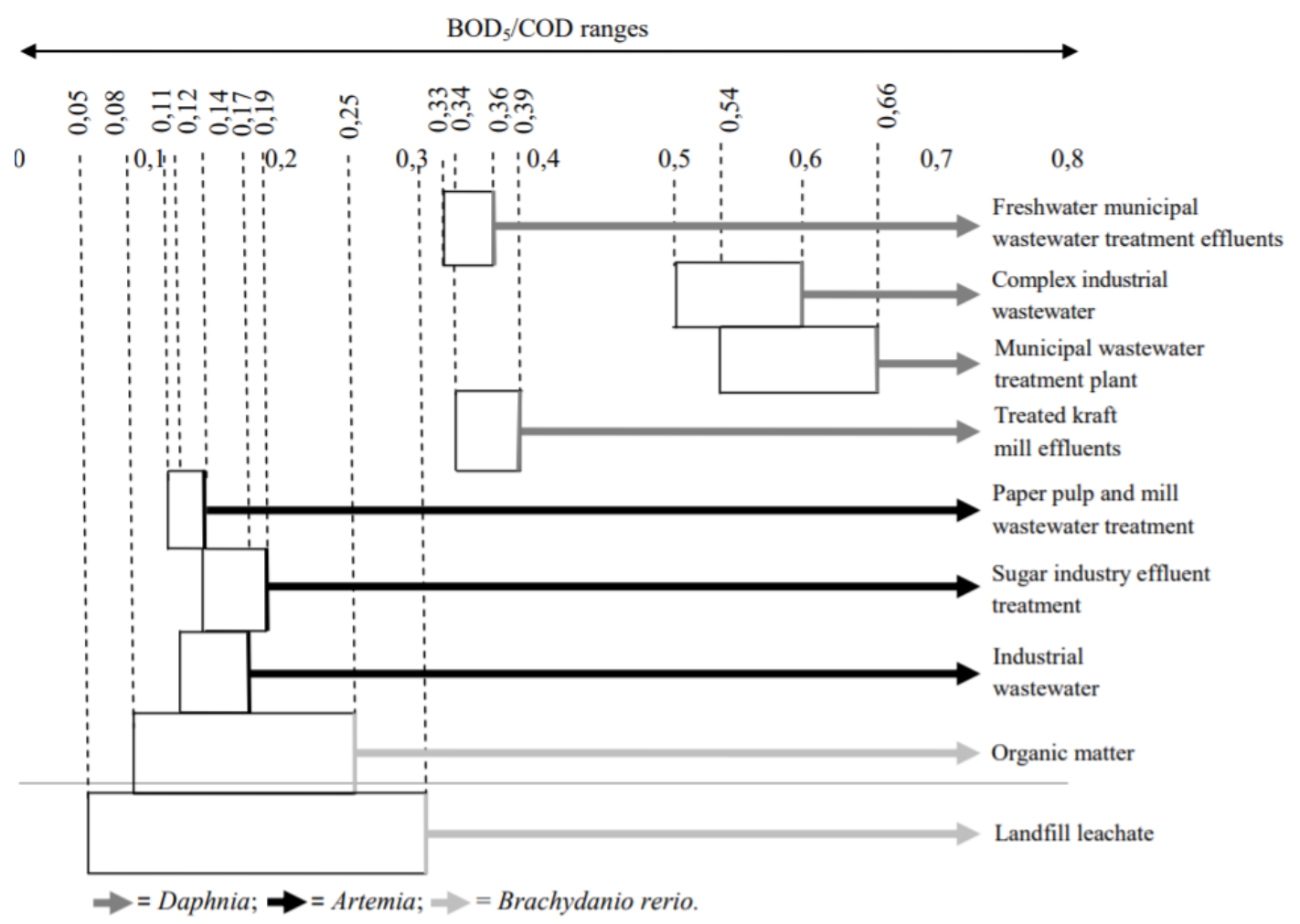

Fig. 4: Comparison of BOD/COD ratio range yielding maximum removal of Daphnia magna, Artemia salina, and Brachydanio rerio 


\section{ACKNOWLEDGEMENTS}

The authors express gratitude to all lecturers of the Department of Environmental Engineering, Faculty of Civil, Environmental, and Geo-Engineering, Institut Teknologi Sepuluh Nopember for every suggestion and viewpoint.

\section{REFERENCES}

Abdalla, K.Z. and Gina, H. 2014. Correlation between biochemical oxygen demand and the chemical oxygen demand for various wastewater treatment plants in Egypt to obtain the biodegradability indices. Int. J. Sci. Basic Appl. Res., 13(1), 42-48.

Al-Rosyid, L.M. and Mangkoedihardjo, S. 2019. Relationship between $\mathrm{BOD} / \mathrm{COD}$ ratio and octanol/water partition coefficient for glucose, lactose, sucrose, formaldehyde, acetic acid, and oxalic acid. Int. J. Civ. Eng. Technol., 10(1): 691-696.

Arslan, O.C. and Karaaslan, M.A. 2016. Bioavailability of sea urchin to aquatic toxicity tests. J. Aquat. Pollut. Toxicol., 1(1), 1-6.

Arun, N.C., Satheesh, K. and Dhivakar, K. 2019. Cultivation of Artemia salina for reducing BOD in industrial wastewater. Int. J. Sci. Res. Rev., 5(07): 1879-1892.

Bambino, K. and Chu, J. 2017. Chapter nine: Zebrafish in toxicology and environmental health. Curr. Top. Dev. Biol., 124: 331-367.

Banch, T.J.H., Hanafiah, M.M., Salem, S., Amr, A., Abbas, F., Alkarkhi, M. and Hasan, M. 2020. Treatment of landfill leachate using palm oil mill effluent. Processes, 8(601): 1-17.

Bekker, E.I., Karabanov, D.P., Galimov, Y.R., Haag, C.R., Neretina, T.V. and Kotov, A.A. 2018. Phylogeography of Daphnia Magna straus (crustacea: Cladocera) in Northern Eurasia: Evidence for a deep longitudinal split between mitochondrial lineages. PLoS One, 13(3): e0194045.

Boix, N., Pique, E., Gomez-Catal, J., Teixido, E. and Llobet, J.M. 2020. Modulation and protection effects of antioxidant compounds against oxidant-induced developmental toxicity in zebrafish. Antioxidants, 9(721): 1-13.

Borba, F.H., Jandira, L., Francine, B., Leandro, P., Jonas, J., Inticher. and Daiana, S. 2019. Pollutant removal and acute toxicity assessment (Artemia salina) of landfill leachate treated by a photo-fenton process mediated by oxalic acid. J. Water Process Eng., (28):159-168.

Borujeni, F.G., Fatemeh, N.B. and Hamed, A. 2018. Data on effluent toxicity and physicochemical parameters of municipal wastewater treatment plant using Daphnia magna. Data in Brief, (19): 1837-1843.

Cabrera, M.N. 2017. Chapter 7: Pulp Mill Wastewater: Characteristics and Treatment. INTECH.

Cardete, M.A., Mata-A.J., Dosta, J. and Nieto-S.R. 2019. Biological nitrification control by addition of folic acid in a petrochemical wastewater treatment focused on organic matter removal. J. Environ. Chem. Eng., 7(2): 102935.

Chamorro, S., Lopez, D., Brito, P., Jarpa, M. and Vidal, G. 2016. Sublethal effects of chlorine-free kraft mill effluents on Daphnia magna. Bull. Environ. Contam. Toxicol., 97(6): 843-847.

Deng, M., Zhang, Y., Quan, X., Na, C., Chen, S., Liu, W., Han, S. and Masunaga, S. 2017. Acute toxicity reduction and toxicity identification in pigment contaminated wastewater during anaerobic-anoxic-oxic (A/A/O) treatment process. Chemosphere, 168: 1285-1292.

Dincer, A.R. 2020. Increasing $\mathrm{BOD}_{5} / \mathrm{COD}$ ratio of non-biodegradable compound (reactive black 5) with ozone and catalase enzyme combination. SN Appl. Sci., Sciences, 2: 736.

El Fels, L., Hafidi, M. and Ouhdouch, Y. 2016. Artemia salina as a new index for assessment of acute cytotoxicity during co-composting of sewage sludge and lignocellulose waste. Waste Manage., 50: 194-200.

Ghosh, P., Thakur, I.S. and Kaushik, A. 2017. Bioassays for toxicological risk assessment of landfill leachate: A review. Ecotoxicol. Environ, Safety 141: 259-270.

Grosser, A., Neczaj, E., Madela, M. and Celary, P. 2019. Ultrasoundassisted treatment of landfill leachate in a sequencing batch reactor. Water, 11 (516): 65-78.

Huang, Y., Campana, O. and Wlodkowic, D. 2017. A millifluidic system for analysis of Daphnia magna locomotory responses to water-born toxicants. Sci. Rep., 7(1): 17603.

Kocbas, F. and Oral, R. 2015. Daphnia magna as a test species for toxicity evaluation of municipal wastewater treatment plant effluents on freshwater Cladoceran in Turkey. Turkish J. Fish. Aquat. Sci., 15: 619-624.

Koppel, N., Maini, R.V. and Balskus, E.P. 2017. Chemical transformation of xenobiotics by the human gut microbiota. Science, 356 (6344)

Kruppert, K., Horstmann, M., Weiss, L.C., Witzel, U., Schaber, C.F., Gorb, S.N. and Tollrian, R. 2017. Biomechanical properties of predatorinduced body armor in the freshwater crustacean Daphnia. Sci. Rep., 7 (9750): 1101-1128

Leppanen, J.J. 2018. An overview of Cladoceran studies conducted in mine water impacted lakes. Int. Aquat. Res., 10: 207-221.

Li, M., Chen, Z., Wang, Z. and Wen, Q. 2018. Investigation on the degradation behavior of dissolved effluent organic matter, organic micro-pollutants, and bio-toxicity reduction from secondary effluent treated by ozonation. Chemosphere, 18 (217): 223-231.

Marzan, L.W., Barua, P., Akter, Y., Mannan, A., Hossain, A. and Ali, Y. 2014. Molecular investigation on clinicopathological, genetic and biochemical changes in Channa punctata infected with internal parasites and subjected to metals pollution in Chittagong, Bangladesh. J. Biomol. Res. Therap., 3: 113.

Mendonça, E., Picado, A., Paixão, S.M., Silva, L., Barbosa, M. and Cunha, M.A. 2013. Ecotoxicological evaluation of wastewater in a municipal WWTP in Lisbon area (Portugal). Desal. Water Treat., (51): 4162-4170.

Moreno, M.I. 2018. Resistance of pathogenic and spoilage microorganisms to disinfectants in the presence of organic matter and their residual effect on stainless steel and polypropylene. J. Glob. Antimicrob. Resist., 14: 197-201.

Organization for Economic Cooperation and Development (OECD). 2019. Section 2 Effects on Biotic Systems: Test Guideline No. 203 Fish, Acute Toxicity Testing. OECD Guidelines for the Testing of Chemicals. https://www.oecd-ilibrary.org/environment/test-no-203-fish-acutetoxicity-test_9789264069961-en

Paris, D. and Mangkoedihardjo, S. 2020. Detoxification of glucose, ammonium, and formaldehyde using nitrification and plant processes. Nat. Environ. Pollut. Technol., 19 (1) 385-388.

Panzica-Kelly, J.M., Zhang, C.X. and Augustine-Rauch, K.A. 2015. Optimization and performance assessment of the chorion-off [dechorinated] zebrafish developmental toxicity assay. Toxicol. Sci., 146 (1): 127-134.

Peitz, C. and Xavier, C.R. 2020. Moving bed biofilm reactor for the treatment of kraft pulp effluent with high organic load rate. Rev. Amb. Água, 15(4), e2512.

Rajabi, S., Ramazani, A., Hamidi, M. and Naji, T. 2015. Artemia salina as a model organism in toxicity assessment of nanoparticles. Daru, 23(1): 20

Ren, Z., Zhang, X., Wang, X., Qi, P., Zhang, B. and Zeng, Y. 2015. AchE inhibition: one dominant factor for swimming behavior changes of Daphnia magna under DDVP exposure. Chemosphere, (120): 252-257.

Sa, L.C.D., Oliveira, M., Ribeiro, F., Rocha, T.L. and Futter, M.N. 2018. Studies of the effects of microplastics on aquatic organisms: What do we know and where should we focus our efforts in the future? Sci. Total Environ., 645: 1029-1039.

Sackey, L.N.A. and Kocí, V. 2020. Assessing the effects of tropical wood leachate on Desmodesmus subspicatus, Lemna minor, and Daphnia magna. Heliyon, 6(7): e04268. 
Smol, M., Włóka, D. and Włodarczyk-Makuła, M. 2018. Influence of integrated membrane treatment on the phytotoxicity of wastewater from the coke industry. Water Air Soil Pollut., 229: 154.

Talalaj, I.A., Biedka, P. and Bartkowska, I. 2019. Treatment of landfill leachates with biological pretreatments and reverse osmosis. Environ. Chem. Lett., 17: 1177-1193.

United States Environmental Protection Agency (USEPA). 2019. Test Guidelines for Pesticides and Toxic Substances. OCSPP Harmonized Test Guidelines. Washington DC, USA.

United States Environmental Protection Agency (USEPA). 2016. Whole Effluent Toxicity Methods Errata Sheet: EPA 821-R-02-012-ES. Washington DC, USA.

Velásquez-Riaño, M., Meneses-Sánchez, J.S. and Arias, C.E.C. 2019. Evaluation of acute toxicity of vinasse by means of Daphnia magna and Aliivibrio fischeri: a comparative study. Interdiscip. Toxicol., 12(3): 143-148.

Xavier, C.R., Daniela, L., Gloria, G., Soledad, C. and Anne, S. 2017. Sensitivity study comparing Daphnia obtusa (Kurz 1874) and Daphnia magna (Straus 1820) exposure to treated kraft mill effluents, diethylstilbestrol, and androstenedione. BioResources, 12(3): 6558-6567.

Xue, F., Tang, B., Bin, L., Ye, J., Huang, S. and Fu, F. 2019. Residual microorganic pollutants and their biotoxicity of the effluent from the typical textile wastewater treatment plants at Pearl River Delta. Sci. Total Environ, (657): 696-703.

Yan, A. and Chen, Z. 2019. Impacts of silver nanoparticles on plants: A focus on the phytotoxicity and underlying mechanism. Int. J. Mol. Sci., 20(5): 1003.

Yasser, E.N., Shawkat, E.N. and Samir, A. 2015. Impact of organic contamination on some aquatic organisms. Toxicol. Int., 22(1): 45-53. 